\title{
Mais um ensaio com Cinamomo, Melia Azedarach, Lin.
}

Tese sôbre silvicultura, apresentada ao II Congresso Panamericano de Agronomia, pelo Prof.

\section{PHILIPPE WESTIN CABRAL DE VASCONCELLOS}

Prof. Cat. da 12a. Cad. e Chefe Técnico da Sec. de Horticultura Escola Superior de Agricultura "Luiz de Queiroz" Universidade de S. Paulo - Piracicaba

\section{INDICE}

Mais, um ensaio com Melia Azedarach, Lin .... ... ... 204 Madeira de Cinamomo .... .... .... .............. 214

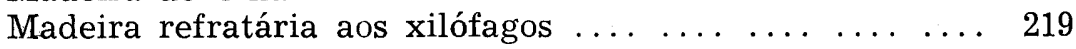

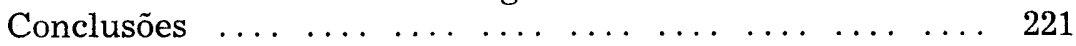

$\begin{array}{lllllllllll}\text { In memoriam } \ldots & \ldots & \ldots & \ldots & \ldots & \ldots & \ldots & \ldots & \ldots & 222\end{array}$

$\begin{array}{llllllllll}\text { Agradecimentos } & \ldots & \ldots & \ldots & \ldots & \ldots & \ldots & \ldots & \ldots & \ldots\end{array}$ 


\section{MAIS UM ENSAIO COM MELIA AZEDARACH, LIN}

Essa planta que é conhecida como "Sicomoro Bastardo" recebeu em nosso país denominações de "Santa Barbara", "Árvore de Para-raio", "Chapeu de Sol" e mais impròpriamente o nome de "Cinamomo", que se tornou muito vulgar.

Tivemos já oportunidade de publicar trabalho a respeito de tal planta (1) que, não obstante exótica, aqui se desenvolve com comportamento surpreendente.

Dispondo nós de uma parcela de "terra roxa" excessivamente pedregosa (mais pedras do que terra) e com grande declive, resolvemos aproveitá-la fazendo uma plantação do Melia Azedarach, Lin, que destinaríamos a produzir combustíve] (lenha). Foto 1.

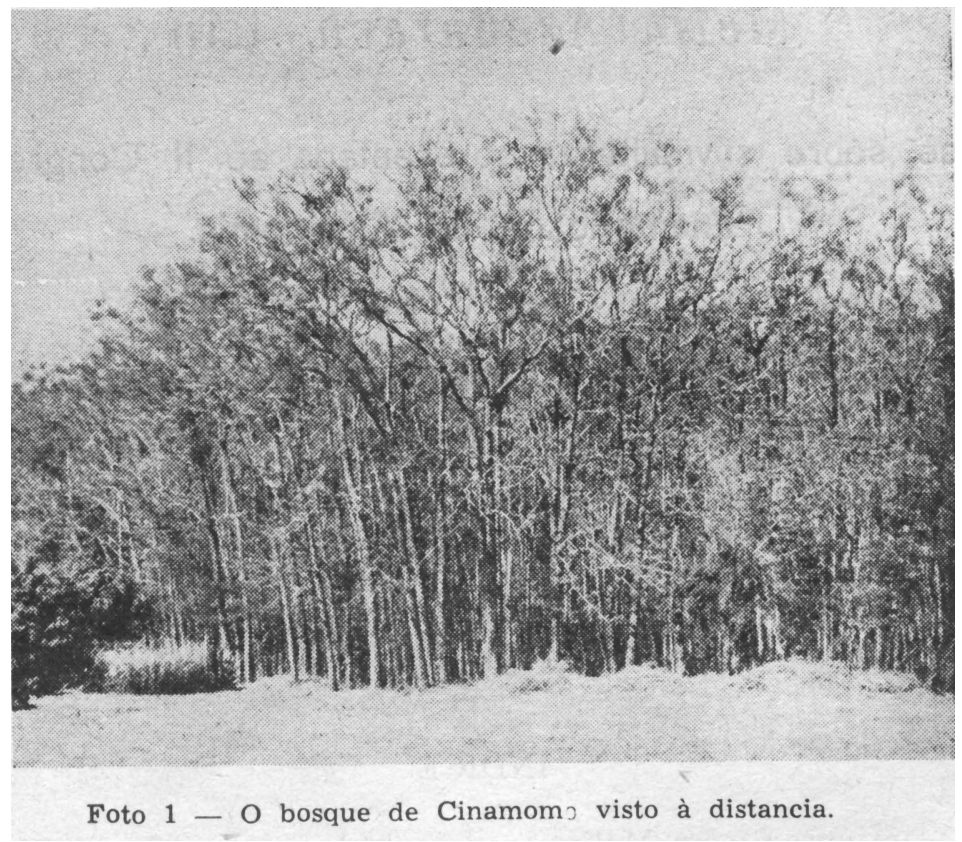

A semeadura, em canteiro preparado, foi feita em 4-9-1928. A germinação deu-se em 8-10-1928. As mudas obtidas foram tardiamente transplantadas em 28-12-1929, inicialmente em número de 460, reduzidas, para retificação de um caminho, a 452. 
O alinhamento escolhido, por causa da declividade do terreno, foi o em triângulo equilátero, de $2,5 \mathrm{~m}$ de lado; portanto a área ocupada por planta foi.

$$
\mathrm{B}=\frac{\mathrm{d}^{2}}{1.155}=\frac{2,5^{2}}{1.155}=\frac{6,25}{1.155}=5,411255 \mathrm{~m}^{2}
$$

ou sejam pràticamente: $5,411 \mathrm{~m}^{2}$.

A área de terreno povoada, foi de $2.446 \mathrm{~m}^{2}$, ou expressa em hectare; 0,2446 .

Como soe acontecer nos terrenos pedregosos onde não se podem empregar máquinas, o trabalho operário se acentua bastante; nos quatro primeiros anos, o quadro seguinte, de nossa conta cultural, o demonstra, com a distribuição pelos meses, das operações realizadas.

Quadro I - Horas de trabalho operário

\begin{tabular}{|c|c|c|c|c|c|c|c|}
\hline DATAS: & 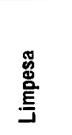 & 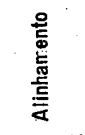 & 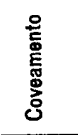 & 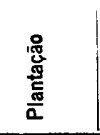 & 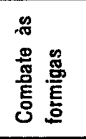 & 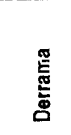 & 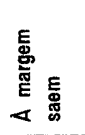 \\
\hline $\begin{array}{l}1929 \text { (28-12) } \\
1930 \text { Janeiro } \\
\text { Fevereiro } \\
\text { Abril } \\
\text { Junho } \\
1931 \text { Maio } \\
1932 \text { Maio } \\
\text { Julho } \\
\text { 1934 Janeiro }\end{array}$ & $\begin{array}{r}110 \\
160 \\
90 \\
\\
60 \\
20 \\
90 \\
50 \\
\end{array}$ & $\begin{array}{c}20 \\
-20\end{array}$ & $\begin{array}{r}80 \\
80\end{array}$ & $\begin{array}{l}40 \\
40\end{array}$ & 20 & 140 & $\begin{array}{r}250 \\
20 \\
160 \\
90 \\
140 \\
90 \\
20 \\
90 \\
50\end{array}$ \\
\hline Somas & 580 & 20 & 80 & 4 & 20 & 140 & 880 \\
\hline
\end{tabular}

Daí por diante, fizeram-se eventuais roçadas do subosque, aguardando a reação das plantas ao estado de "maciço cerrado".

Notámos logo que certa porcentagem delas tomava vulto em diâmetro, máo grado as más qualidades físicas do solo. No nono ano observámos reação generalizada pela falta de espaço entre as copas, com a consequente apresentação de brotações para o lado basilar dos fustes. Indicava isso que o desbaste deveria ter sido feito no quinto ou sexto ano, pois, de acôrdo com 
nossas observações nessas idades as plantas já entram em frutificação.

A seguir reiirámos tôdas as dominadas em número de 158 ; produziram sómente 7,5 (sete e meio) esteres de lenha.

Com isso só observámos o maciço com aspecto muito mais raleado e cessou a brotação da base dos fustes; muitas plantas apresentaram um aumento de diâmetro razoável e no décimo quarto e décimo quinto ano as copas revelavam afrouxamento em sua vegetação. Esperámos até o décimo sexto, sem que melhorassem (Foto 2). Resolvemos então fazer o corte e analisar a produção.

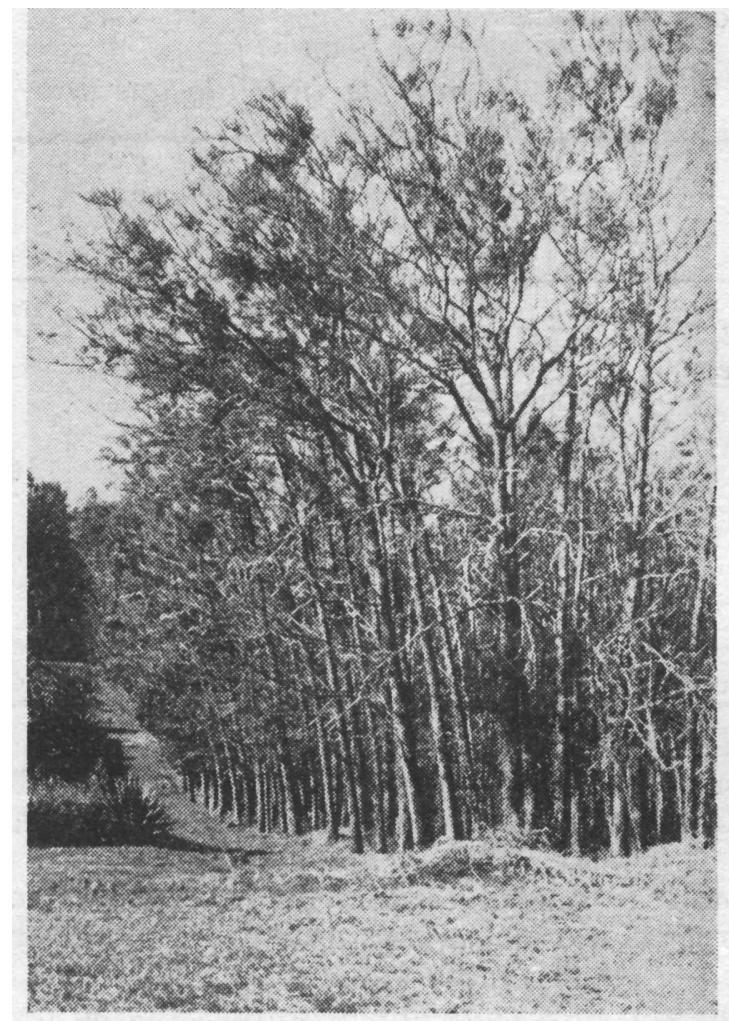

Foto 2 - Aguardado o corte para o 16.o ano, não houve grande melhoria. 
Em primeiro lugar foi examinada a altura que atingiram as árvores. Para êsse e para exames subsequentes dividimo-las, em três categorias :

I) Arvores de mais fraco desenvolvimento volumétrico que aqui aparecem como "retardatarias" e cujos diâmetros à altura do peito (DAP a $1,50 \mathrm{~m}$ ) atingissem a $0,20 \mathrm{~m}$ inclusive.

II) As que chamámos "de desenvolvimento volumétrico médio", cujos diâmetros estavam compreendidos acima daquela medida e abaixo de $0,26 \mathrm{~m}$.

III) Arvores "avantajadas", cujos diâmetros eram de $0,26 \mathrm{~m}$ ou maiores.

O quadro a seguir revela as frequências das alturas.

Alturas dos cimos de 180 árvores e suas frequências

\begin{tabular}{|c|c|c|c|c|c|c|}
\hline \multirow[b]{2}{*}{ Metros } & \multicolumn{2}{|c|}{ 1) RETARDATARIAS } & \multicolumn{2}{|c|}{ 11) DESENVOLV. MÉDIO } & \multicolumn{2}{|c|}{ III) AVANTAJADAS } \\
\hline & Até D.SP & $0 \mathrm{~m}$ inclusive & $\begin{array}{r}\text { DAP acl } \\
0\end{array}$ & $\begin{array}{l}0,20 \mathrm{~m} \text { aí } \\
\text { lusive }\end{array}$ & DAP $=$ & m • acima \\
\hline $\begin{array}{l}\text { Acima de } \\
15 \text { até } 16 \\
16 \text { até } 17 \\
17 \text { até } 18 \\
18 \text { até } 19 \\
19 \text { até } 20 \\
20 \text { até } 21 \\
21 \text { até } 22\end{array}$ & $\begin{array}{r}\mathrm{N} . \\
0 \\
3 \\
8 \\
12 \\
31 \\
21 \\
1\end{array}$ & $\begin{array}{c}\% \\
0 \\
3,94 \\
10,52 \\
15,78 \\
40,76 \\
27,61 \\
1,31 \\
\end{array}$ & $\begin{array}{r}\mathrm{N} . \\
1 \\
0 \\
2 \\
1 \\
16 \\
24 \\
4 \\
\end{array}$ & $\begin{array}{c}\% \\
1,85 \\
0 \\
3,70 \\
12,95 \\
29,61 \\
44,42 \\
7,40 \\
\end{array}$ & $\begin{array}{r}N . \\
3 \\
2 \\
0 \\
5 \\
16 \\
21 \\
3\end{array}$ & $\begin{array}{c}\% \\
6,0 \\
4,0 \\
0 \\
10,0 \\
32,0 \\
420 \\
6.0\end{array}$ \\
\hline Exemplares & 76 & & 54 & & 50 & \\
\hline
\end{tabular}

Conforme verificámos por êstes dados, a maior frequência das retardatárias $(40,76 \%)$, está acima de 19 , até $20 \mathrm{~m}$ inclusive, ao passo que as de desenvolvimento médio e avantajadas estão acima de $20 \mathrm{~m}$, até 21 inclusive, com as frequências respectivamente de 44,42 e $42,0 \%$. No compasso adotado as alturas obtidas foram mais que satisfatórias e fazemos notar que nenhuma árvore passou acima de $22 \mathrm{~m}$.

Vejamos agora que aconteceu com os fustes: 

Anais da E. S. A. "Luiz de Queiroz"

Alturas das fustes de 180 árvores e suas frequências

\begin{tabular}{|c|c|c|c|c|c|c|}
\hline Metros & \multicolumn{2}{|c|}{ I) RETARDATARIAS } & \multicolumn{2}{|c|}{ 11) DESENVOLV. MÉDIO } & \multicolumn{2}{|c|}{ III) AVANTAJADAS } \\
\hline Acima de & N. & $\%$ & N. & $\%$ & N. & $\%$ \\
\hline 3 até 4 & 0 & 0 & 0 & 0 & 1 & 2,0 \\
\hline 4 até 5 & 0 & 0 & 0 & 0 & 1 & 2,0 \\
\hline 5 até 6 & 1 & 1,31 & 1 & 1,85 & 2 & 4,0 \\
\hline 6 até 7 & 3 & 3,94 & 1 & 1,85 & $\overline{3}$ & 6,0 \\
\hline 7 até 8 & 8 & 10,52 & 5 & 9,25 & 14 & 28,0 \\
\hline 8 até 9 & 6 & 7,89 & 6 & 11,10 & 7 & 14,0 \\
\hline 9 até 10 & 21 & 27,61 & 12 & 22,21 & 6 & 12,0 \\
\hline 10 até 11 & 23 & 30,24 & 18 & 33,31 & 5 & 10,0 \\
\hline 11 até 12 & 12 & 15,78 & 10 & 18,51 & 9 & 18,0 \\
\hline 12 até 13 & 2 & 2,63 & 1 & 1,85 & 2 & 4,0 \\
\hline Exemplares & 76 & & 54 & & 50 & \\
\hline
\end{tabular}

Pelo quadro presente verificámos que retardatárias e médias em mais de $50 \%$ para cada categoria, apresentavam seus fustes acima de 9 até $11 \mathrm{~m}$ ao passo que as volumètricamente avantajadas tiveram sua maior frequência nas alturas acima de 7 até $8 \mathrm{~m}$ inclusive. Se um segundo desbaste do bosque houvesse sido feito em tempo hábil, conforme preconisámos a princípio, muito maior seria o número de plantas volumètricamente avantajadas e melhor providas de diâmetro, associado a fuste mais alto, pois que as copas encontrariam espaços laterais consentâneos com sua expansão.

No que toca aos acréscimos diametrais, bem esclarecem os quadros que s seguem :

DAP (a $1 \mathrm{~m}, 50)$ de 180 árvores exploradas e suas frequências

\begin{tabular}{|c|c|c|}
\hline \multicolumn{3}{|c|}{ 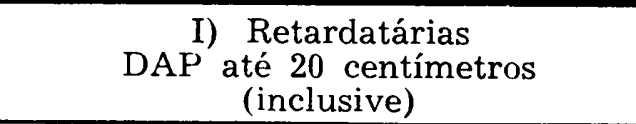 } \\
\hline Acima de & $\mathrm{N}$. & $\%$ \\
\hline 9 até 10 & 1 & 1,31 \\
\hline 10 até 11 & 0 & \\
\hline 11 até 12 & 1 & 1,31 \\
\hline 12 até 13 & 2 & 2,63 \\
\hline 13 até 14 & 6 & 7,89 \\
\hline 14 até 15 & 12 & 15,78 \\
\hline 15 até 16 & 11 & 14,46 \\
\hline 16 até 17 & 18 & 23,67 \\
\hline 17 até 18 & 10 & 13,15 \\
\hline 18 até 19 & 8 & 10,52 \\
\hline 19 até 20 & 7 & 9,20 \\
\hline Exemplares & 76 & \\
\hline
\end{tabular}


II) Desenvolvimento Médio

(Acima de 0,20 até 0,26 exclusivo)

DAP - (centímetros)

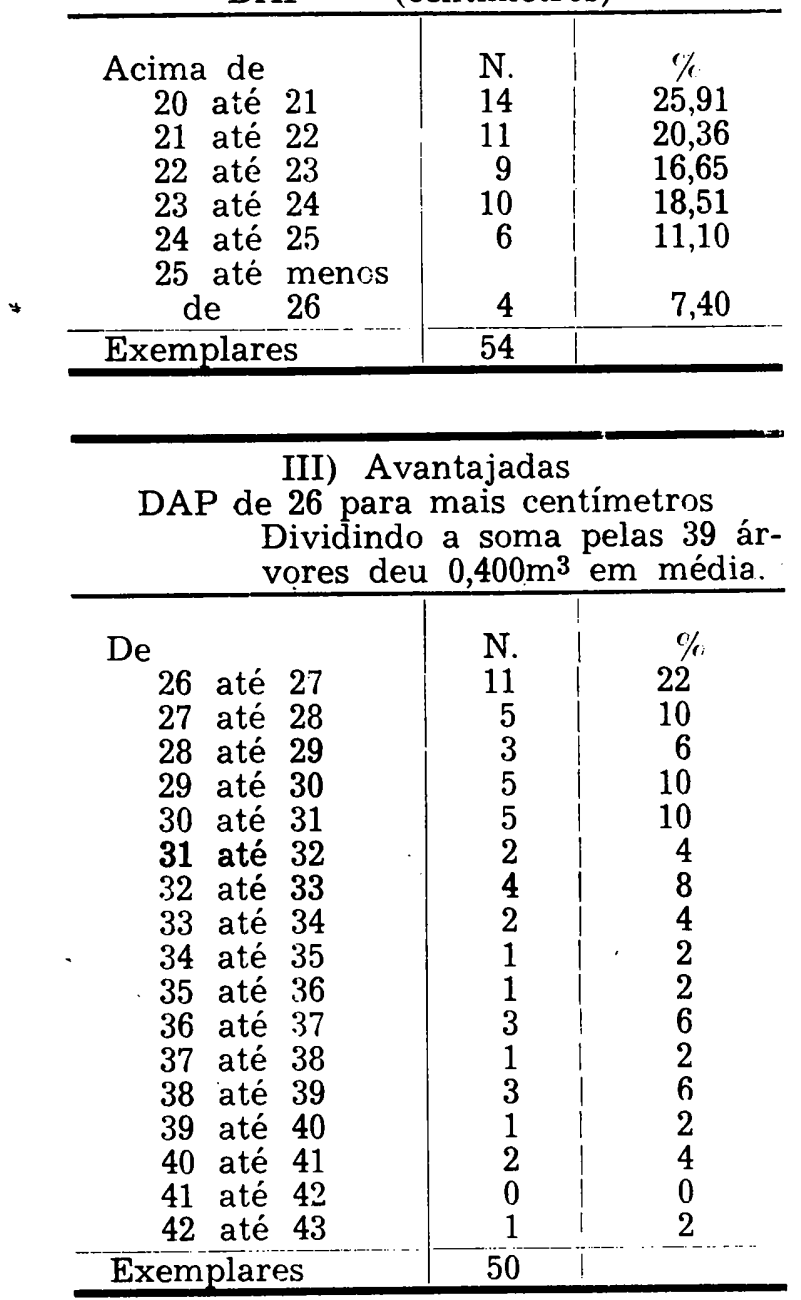

Por ai se vê que as retardatárias apr ssentam sua maior frequência $(23,67 \%)$ com diâmetros, à altura do peito, acima de $16 \mathrm{~cm}$ até 17 inclusive, o que representou para essa categioria inferior o aumento de 1 centímetro por ano. As médias na sua maior frequência $(25,9 \%)$ nos diâmetros acima de 20 até 21 produziram aumento de $1,250 \mathrm{~cm}$. As avantajadas na sua maior 
frequência de $22 \%$ nos diâmetros de 26 a $27 \mathrm{~cm}$ mostravam o aumento anual de $1,6 \mathrm{~cm}$. Esses acréscimos reputâmo-lo baixos para essa essência mas a natureza do solo excessivamente pedregoso e a falta de desbastes oportunos justificam-nos. O motivo determinante da separação entre árvores médias e de DAP 0m,26, foi que dentre estas já se apresentaram exemplares aceitos pela Serraria.

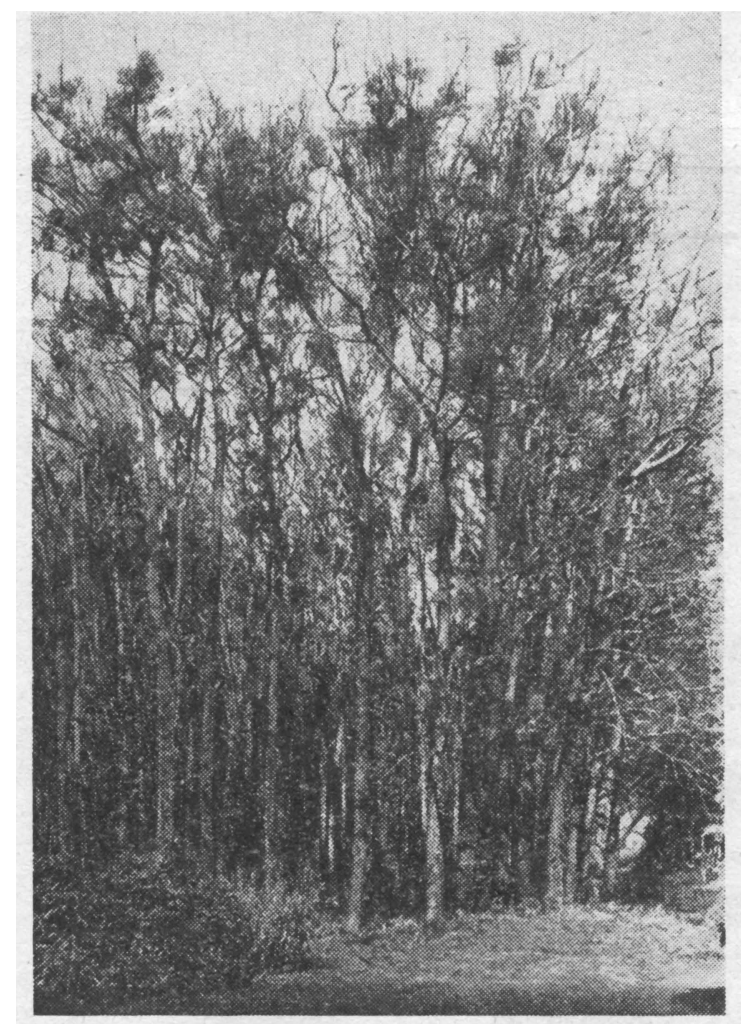

Foto 3 - Vêem-se as árv res do bosque na última etapa com as cópas parasitadas por hervas de passarinho, (Loranthaceas que muito as aprec am)

Para avaliar tôda a produção do bosque (Fotos 3 e 4) sob a forma de lenha, trabalhamos 180 árvores categorizando os produtos (desprezando os de menor diâmetro do que $0 \mathrm{~m}, 09$ ) (abaixo da bitola "de garrafa") que foram cedidos aos trabalhadores. 


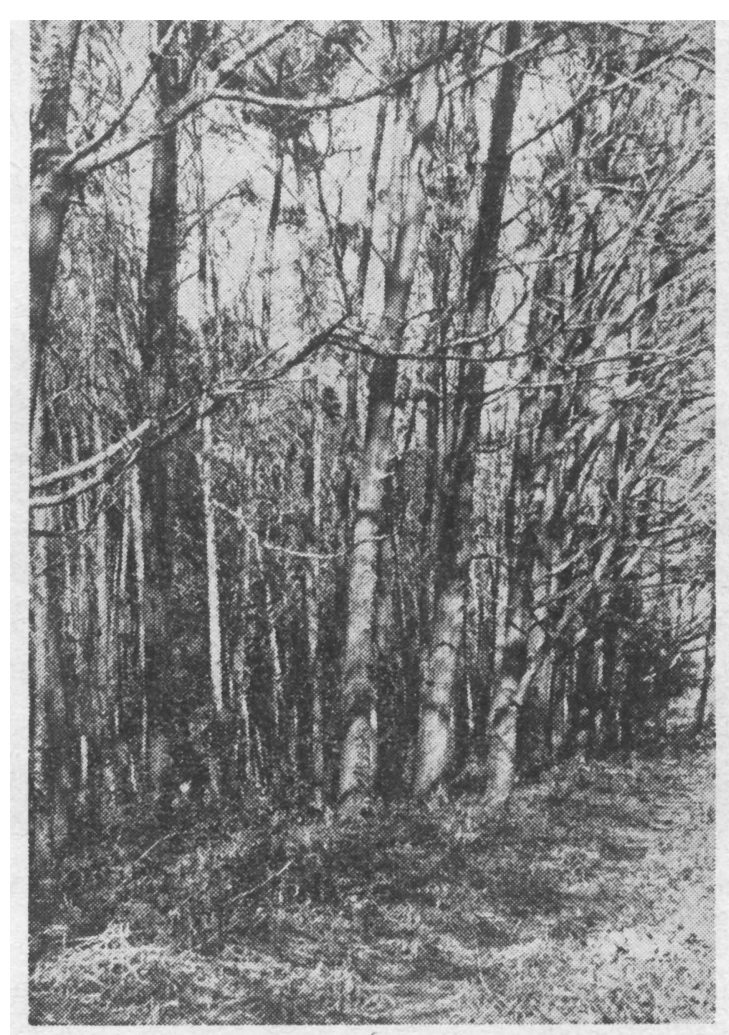

Foto 4 - Não seria curial destinarem se todas estas plantas a lenha.

\section{I}

Bitolas e quantitativos de lenha das copas (Foto 5) de 220 árvores exploradas :

Diâmetros basilares
das peças

$\mathrm{m}$

0,09

0,10

0,11

0,12

0,13

0,14

Soma
E'sieres

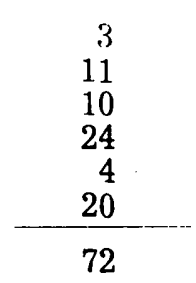



esteres.

Cada copa produziu pois, (desprezada a lenha fina) 0,327

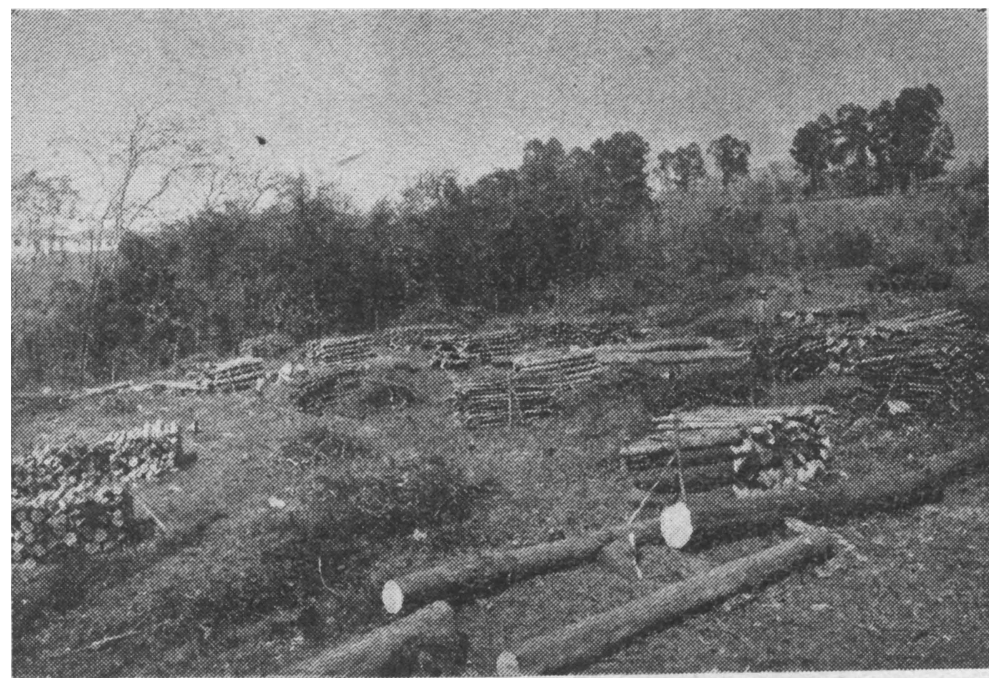

Foto 5 - De permeio à lenha empilhada, das cópas, vêem-se ao longe os tóros das "árvores avantajadas".

A seguir, o rendimento que obtivemos de lenhas direitas de fustes e hastes:

Bitolas de lenhas reta de fustes e hastes (foto 6), de 220 árvores exploradas :

Diâmetros basilares das peças

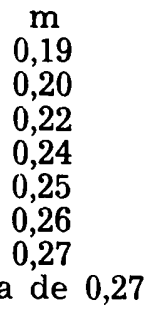

Soma

\section{Esteres}

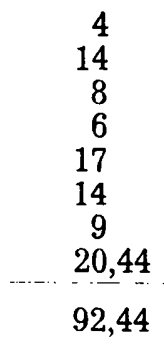

Ou sejam 0,420 de estere, por árvore. 
O bosque em exploração, com as medições que foram feitas apresentou, estimando-se a sua produção total como se fôra sòmente de lenha, o seguinte resultado:

Lonha grossa e reta foto 6 Lenha de copas
(de fustes o hastes)

Categorias

N. de plantás

Esteres

Esteres

Médias

Retardatárias

Avantajadas

124
112
58
294

31,35

39,98

48,70

120,03

19,76

52,65

45,56

117,97

Teremos por árvore do corte final, 0,843 esteres.

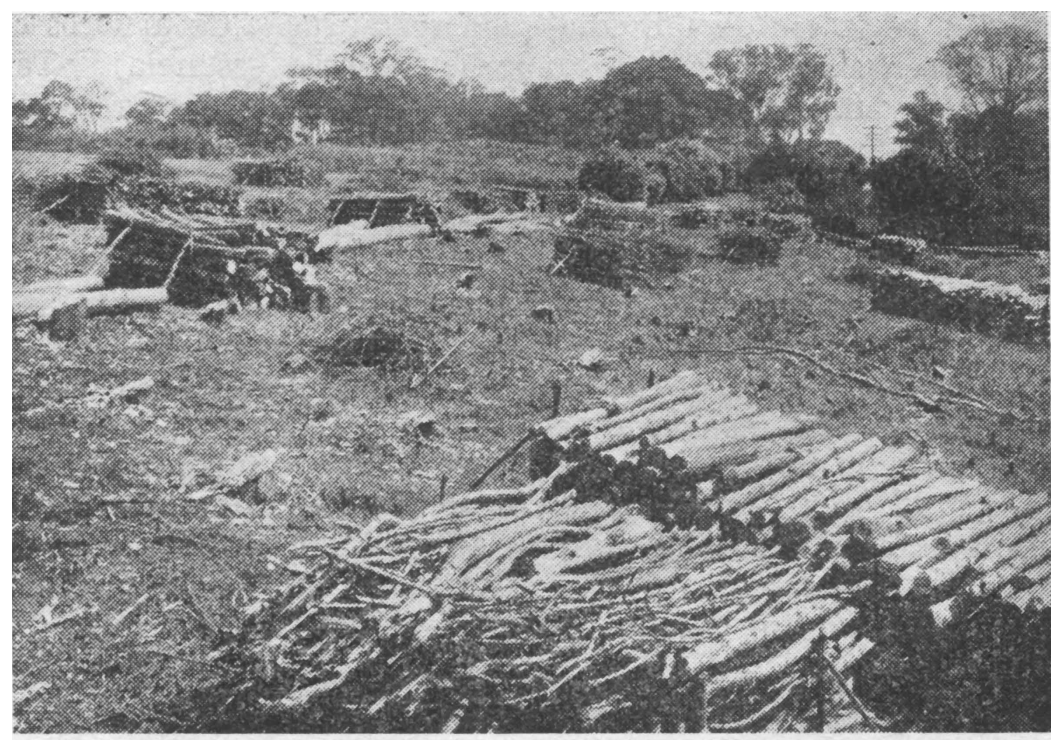

F to 6 - Muitas pilhas de lenha reta, de fustes. Aparecem à esquerda e ao fundo, tóras das árvores avantajadas.

Somando-se os esteres produzidos pelos fustes e hastes 120,03 com das copas 117,97 e mais cs do desbaste há anos feito das dominadas, 7,5, teremos o total de lenha que foi de 245 esteres para a área de $2.446 \mathrm{~m}^{2}$, o que nos dá :

Esteres por hectare $1.003,67$ e por alqueire paulista .. .. $\left(24200 \mathrm{~m}^{2}\right) \quad 2.428,88$.

Isso conforme dissemos sem computar a lenha abaixo de 0,09 de diâmetro. Observando que as cepas que restaram d's 
corte tornavam-se bem providas de vergônteas o que demonstra que as gemas dormentes (proventícias) conservaram-se com vitalidade, mandámos fazer uma contagem rápida e respectiva mensuração, cêrca de seis meses (17-2-1948), após o corte.

Cepas

N. de vergônteas

Alt. das vergônteas

\begin{tabular}{r|r|r|r|r|r|r|r}
\hline 1 & 2 & 3 & 4 & 5 & 6 & 7 & 8 \\
10 & 13 & 15 & 17 & 19 & 8 & 18 & 9 \\
\hline 3,45 & 5,50 & 4,20 & 2,60 & 6,0 & 2,70 & 3,90 & 4,90 \\
\hline
\end{tabular}

Ésse fato veio demonstrar a pussibilidade de estabelecer, a seguir, o regimem de talhadia, pela restauração de árvores que já apresentavam bastante idade (para essa essência). Também observámos a faculdade que tem de emitir brotos das raízes expostas ou contundidas que vêm adensar o povoamento dos lenheiros, onde o temperamento flexível, também quanto à luz, permite uma exploração em regimem de talhadia esquadrinhada.

Entretanto devemos prevenir a quem queira aproveitar as copas remanescentes para estabelecer uma talhadia, que não deverá expôr o interior dos maciços, como flanco, à furia das tempestades. Isso nos aconteceu levando o corte por etapas a partir do lado noroeste para sudoeste; uma tempestade derrubou-nos de uma vez, dez árvores sendo que duas delas foram completamente desarraigadas. Se tivesse sido feito em direção contrária, as linhas de borủu, exposías e enrigecidas de lado do noroeste, teriam defendido o remanescente, atraz dessa barreira natural.

Quanto às ótimas qualidades da lenha já tivemos oportunidade de emitir a nossa opinião em outra publicação (1).

\section{MADEIRA DE CINAMOMO}

Mas esta essência que tem tantos nomes vulgares (1): "Sicomoro bastardo", dos portugueses; "False sycomore" dos ingleses, "Lilas des Indes ou du Japon" dos franceses, "Sendan dos japoneses, etc. dá tão preciosa madeira para móveis (Foto 7) e construções internas que é uma iniquidade dar-selhe a aplicação como combustível. Senão vejamos mais uma vez o que pudemos fazer com alguns produtos do bosque de 
que vimos tratando. Depois de irmos cortando a eito e de medir como se fossem para lenha retirámos 39 árvores das 58 avantajadas e mandámo-las para a Serraria Cobra (em Piracicaba). Essas 39 árvores produziram 50 toros nas condições prescritas isto é, de terem no mínimo, $25 \mathrm{~cm}$ de diâmetro no lado mais fino. Os fustes com os respectivos números das árvores na plantação foram medidas diretamente e procedemos ao cálculo do "volume cilíndrico" como se vê neste quadro:

$\begin{array}{cccc}\text { Arvores } & \text { Metr. cúbicos } & \text { Arvores } & \text { Metr. cúbic.s } \\ 1 / 1 & 0,6183 & 4 / 19 & 0,2070 \\ 1 / 2 & 0,1970 & 5 / 1 & 0,5965 \\ 1 / 3 & 0,2443 & 5 / 2 & 0,5614 \\ 2 / 1 & 0,5736 & 5 / 4 & 0,2347 \\ 2 / 2 & 0,4735 & 5 / 20 & 0,4821 \\ 2 / 3 & 0,2691 & 5 / 23 & 0,5937 \\ 2 / 4 & 0,5038 & 5 / 24 & 0,3675 \\ 2 / 5 & 0,4351 & 5 / 26 & 0,4789 \\ 2 / 6 & 0,2862 & 6 / 1 & 0,2708 \\ 2 / 9 & 0,4580 & 6 / 33 & 0,1889 \\ 2 / 10 & 0,8482 & 7 / 29 & 0,30178 \\ 3 / 1 & 0,2920 & 7 / 30 & 0,2093 \\ 3 / 2 & 0,1911 & 8 / 29 & 0,2093 \\ 3 / 6 & 0,2175 & 8 / 34 & 0,6353 \\ 3 / 8 & 0,2862 & 9 / & 0,5147 \\ 3 / 11 & 0,2647 & 10 / 1 & 0,3201 \\ 3 / 12 & 0,5066 & 12 / 1 & 0,5725 \\ 3 / 14 & 0,5572 & 39 & 15,6074 \\ 3 / 15 & 0,3958 & & \\ 4 / 9 & 0,3756 & & \\ 4 / 17 & 0,6641 & & \\ 4 / 18 & 0,1970 & & \end{array}$

Ésses 15.607 metros cúbicos do volume cilíndrico dão 12.257 de madeira esquadrada ao quarto sem dedução, pois que é, tal essência, muito rica em cerne.

A Serraria Cobra, aceitou a nossa proposta de serrar de parceria (à meia) ficando na obrigação de nos prestar informações escritas dos volumes de peça por peça numerada $\epsilon$ constam do nosso arquivo.

Deixada secar ao ar nos páteos da Serraria; já em 5 de abril de 1948 estava ela entregando a madeira serrada, da coparticipação da nossa Secção Técnica de Horticultura que a seguir remeteu-a à Oficina de Carpintaria da Escola. 


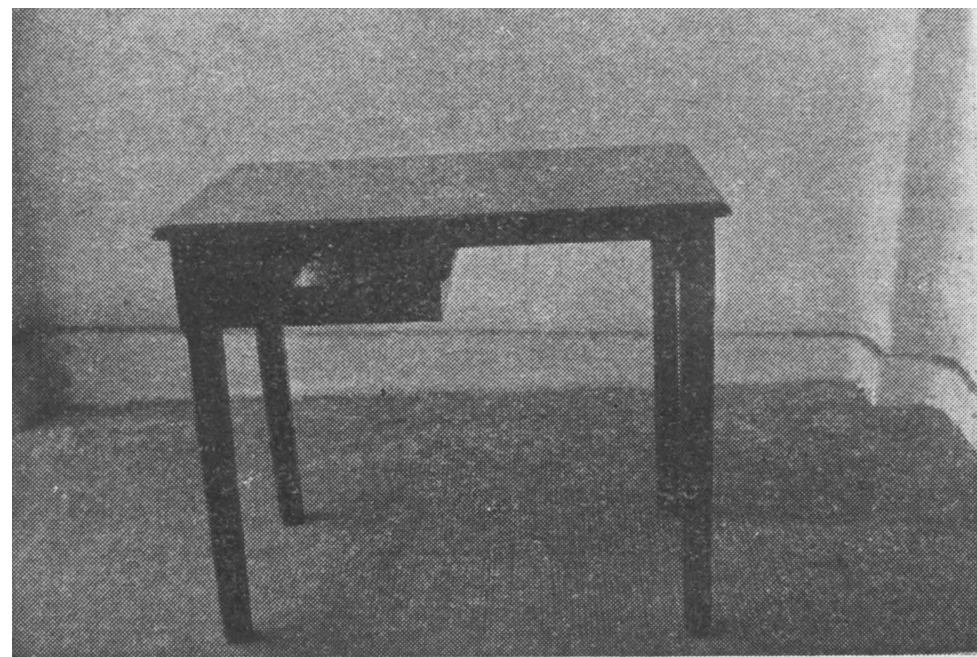

Foto 7 - Mesa de madeira de "cinamomo" (árvore de 14 anos), construida em: 18-8-1928, ainda agora em uso e perfeita forma.

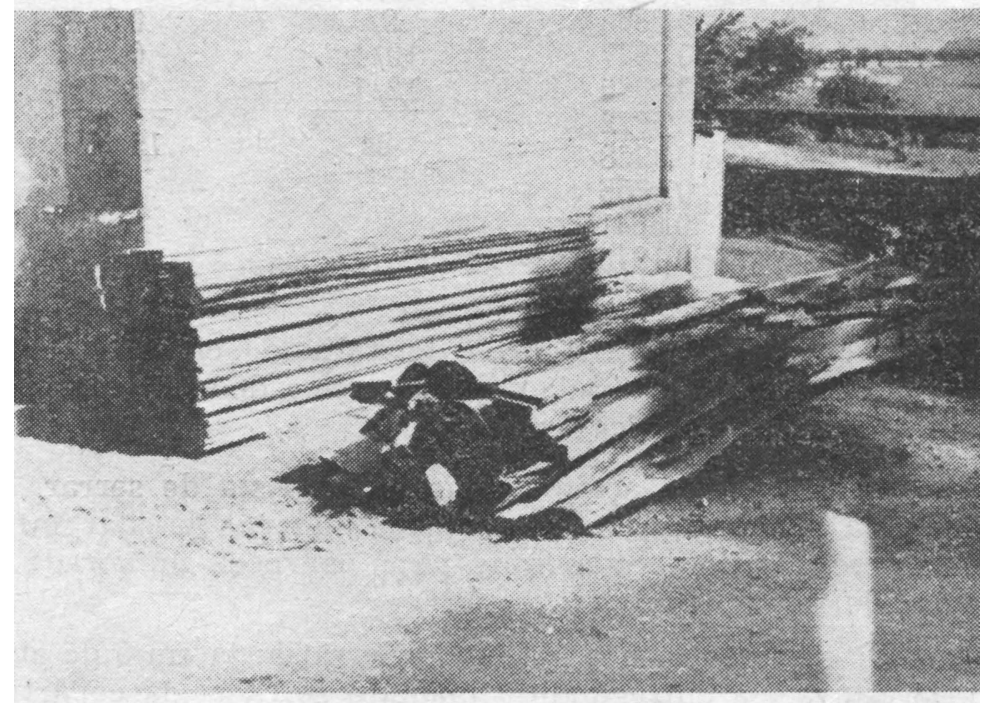

Foto 8 - Uma pilha de tabuas de cinamomo chegadas da Serraria Cobra. Ao lado, as costaneiras. 
Vamos analisar uma das notas de entrega para termos noção do valor dêsse material que medimos. Constava (Fotos 8 e 9) de 60 das 120 tábuas, isto é, a metade das que preparara com parte do volume das 39 árvores.

$\begin{array}{ccc}\text { Largura } & \text { Espessura } & \begin{array}{c}\text { Soma dos } \\ \text { comprimentos }\end{array} \\ 0,16 & 0,025 & 3,88 \\ 0,17 & 0,020 & 74,65 \\ 0,17 & 0,025 & 22,77 \\ 0,18 & 0,020 & 42,90 \\ 0,18 & 0,025 & 20,66 \\ 0,19 & 0,020 & 11,66 \\ 0,19 & 0,030 & 9,04 \\ 0,20 & 0,025 & 3,87 \\ 0,21 & 0,020 & 24,50 \\ 0,21 & 0,025 & 15,59 \\ 0,25 & 0,020 & 23,71 \\ 0,25 & 0,025 & 5,89 \\ 0,25 & 0.030 & \\ & & 264,99\end{array}$

O volume das 60 tábuas foi de $1 \mathrm{~m}, 283$.

A cubicação correspondente às 120 táboas, teria sido portanto de $2,567 \mathrm{~m}^{3}$ com a extensão linear de $529, \mathrm{~m} 98$. Os preços que se pagam por tábuas um pouco mais largas, porém, de madeira que não serve para confeç̧ão de móveis é de 40 cruzeiros por metro linear. Conservando-se o mesmo para as mais estreitas, porém de melhor qualidade e servindo para confecção de mobiliário, ter-se-ia o montante de $\mathrm{Cr} \$ 21.199,20$; isso sòmente para essa fração da madeira das 39 árvores avantajadas de um total de 58 que o bosque possuia. Ao nos informarmos com o sr. Pedro Cobra, proprietário da Serraria e que também mantém nela uma secção de carpintaria, sôbre as qualidades da madeira dos Cinamomos, que lhe enviámos, disse-nos ter achado otima para múltiplas aplicações que dela fizera.

Inquirindo-nos sôbre a idade e condições da cultura dessa essência florestal, declarou-nos que iria cultivá-la. Eis aí, diante dos fatos irretorquíveis e para gáudio nosso, mais, um dentre os muitos convertidos à Silvicultura, com o Cinamomo.

Outro proprietário de Serraria e Carpintaria, o sr. Angelo Perecin, ao examinar algumas peças serradas que haviamos encostado havia meses, à parede de um prédio, expostas ao sol poente e às chuvas e que não apresentavam empeno, exclamou 


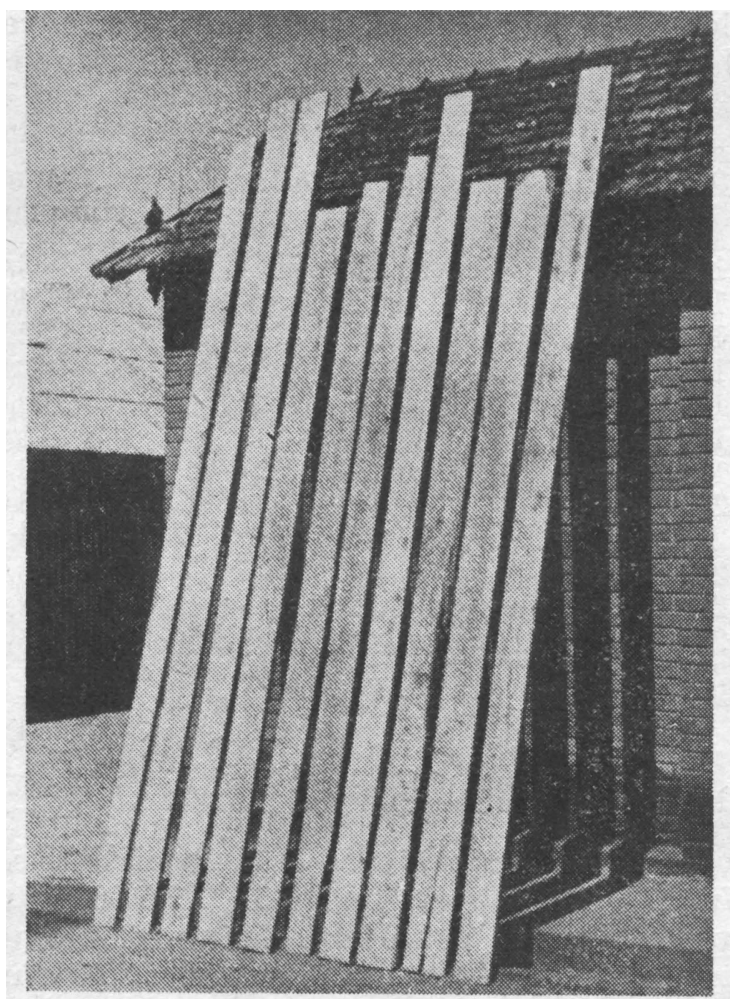

Foto 9 - Algumas das taboas mais longas, ao lado de um telhado para mostrarem os seus comprimentos.

admirado: esta madeira servirá para confecção de tacos (parquets).

A pequena mesa que apresentamos na (Foto 7) e que, com aspecto de nova, continua sempre ao lado de nossa escrivaninha de trabalho, foi construida em 18-8-1928, só uma vez teve as tábuas reapertadas e então reinvernizadas não obstante ter recebido algumas chuva na proximidade de uma janela e já ter viajado para apresentar-se em exposições.

Se tomarmos como base o resultado obtido com a fração do volume daquelas 39 árvores avantajadas e sabendo-se que o bosque apresentava 58 delas, é fácil deduzir-se quão rendosas se apresentariam se exploradas tôdas; senão vejamos : 
Ora, 39 árvores deram $\mathrm{m}^{3}$ 12,257 de madeira esquadriada a) $4^{\circ}$. sem dedução, 59 darão $\mathrm{m}^{3} \quad 18,22$.

$\mathrm{E}$ ainda $\mathrm{se} \mathrm{m}^{3} 2,567$ nos renderam valor em táboas de Cr $\$ 21.199,00$, cs 18,22 dar-nos-iam a quantia "astronômica" de Cr\$ $\$ 150.465,00$ ou Cr $\$ 2.594,00$ por árvore avantajada.

Teremos a notar ainda, ao relatarmos dizendo que muitas plantas das médias dariam, serradas, excelentes peças de 8 e mais metros de comprimento, percebemos no industrial certo arrependimento de não as ter aproveitado, (limitou a $0 \mathrm{~m}, 25$ o diametro do lado da ponta) deixando que fossem levadas como lenha, porque desconhecia as qualidades da madeira de cinamomo.

O que é fato: depois de nossa publicação (1) em 1928 por tôda parte estão havendo plantações dessa essência que já foi, com razão, chamada "Arvore santa" e nós constantemente consultados sôbre sua cultura e exploração. Só uma emprêsa estrangeira declarou-nos após a consulta que iria plantar sessenta alqueires, de uma vez.

\section{MADEIRA REFRATARIA AOS XILÓFAGOS}

E' uma notícia alvissareira áqueles que se vêm às voltas com terrível combate a êsses destruidores das madeiras, desde os de fundos dos guarda-roupas até às peças artisticamente entalhadas: o cinamomo tem-se revelado imune a êsses ataques. Temos tocos guardados com data de $1933 \mathrm{em}$ promiscuidade com os de outras madeiras fortemente atacadas e que nada de prejuizo, apresentam, mesmo no alburno e casca.

\section{Area cultural - Temperamento}

Pelo que se verifica, pelo menos em São Paulo e para 0 Sul essa essência cresce com grande vigor acomodando-se a solos muito diversos mostrando um temperamento bastante frugal. Os estados sulinos costumam plantá-la como arborização de avenidas, ruas e estradas; as provas ecológicas estão portanto já feitas. Será necessário que se ensaie também no norte e nordeste brasileiro onde provàvelmente dar-se-á também e positivado isso será um grande recurso florestal.

\section{- Combustivel}

Já tivemos ocasião de nos referir (1) que sua lenha pode ser queimada sem estar sêca. Além disso no momento de sua 
combustão nota-se desprèndimento de bastantes gases combustíveis; os ramos poderão ser aproveitados para produzir gás de madeira, em abundância.

\section{Subosque}

O subosque do maciço tinha uma vegetação vigorosa. E' possível portanto que se preste à cultura silvo-pastoril, formando-se pasto, sob as ávores já desenvolvidas. Além das argumentações que já há tempos apresentámos sôbre não serem tidas como plantas venenosas (1), acrescentaremos esta, que nos narrou o Dr. Edmundo Navarro de Andrade: "em certa ocasião as vacas de raça fina, da Fazenda do Dr. Martinho Prado, escaparam penetrando por entre a plantação de cinamomo que estava frutificando, tendo ingerido os frutos que eram tidos como venenosos. Houve grande apreensão dos responsáveis; como resultado - elas produziram mais leite, na ordenha do dia seguinte..."

Se nós compararmos a produção de tal bosque artificial com as nossas matas seculares, ficamos admirados em vêr a superioridade dele em produção, mesmo mal conduzido (orientado para produção de combustível e ao depois aguardando um pouco mais de tempo retirando também madeira de construção).

Este quadro poderá elucidar sôbre êsse misto de produção que tivemos, em confronto com informações dadas por exploradores de matas naturais que existiram nos arredores:

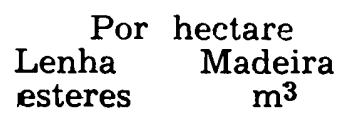

495

800

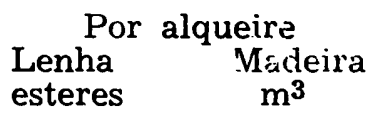

1.200

100

Cinamomo

com $161 / 2$ anos

Nas matas naturais tirariamos peças de muito maioreș dimensões mas de qualidades heterogêneas. $O$ quantitativo da floresta artificial em foco é enormemente maior e obtido em lapso de tempo curtissimo. 


\section{CONCLUSÕES}

I) A essência florestal Melia Azedarach Lin deve ser cultivada, especialmente visando-se a produção de madeira para construções internas, mobiliário, caixotaria, etc.

II) Os produtos secundários daquela exploração (copa e ramada) dão abundante e ótimo combustível.

III) Sua madeira (de cerne e mesmo de alburno) tem-se revelado imune ao ataque pelos xilófagos, mesmo guardada de mistura, por mais de vinte anos, com peças atacadas, de outras essências florestais.

IV) Móvel construido com madeira de Melia Azedarach de 14 anos, em 18-8-928 está ainda hoje em perfeita forma e com aspecto de novo.

V) E' de precocidade assombrosa, fornecendo ótimos produtos para aquelas finalidades, mais cedo que qualquer outra essência florestal por nós observada.

VI) A sua frugalidade fá-la acomodar-se a solos (p.ex. o pedregoso em que fizemos experiências) imprestáveis para a lavoura.

VII) O compasso adotado por nós nesta experiência $(2,5 \mathrm{~m}$ em triângulo equilátero) produziu alturas totais e de fustes que jamais haviamos observado para essa essência.

VIII) Mesmo sem limpesas e desbastes oportunos alcançou como vimos, para os produtos, valôres inesperados.

IX) As observações que fizemos no povoamento em tal compasso, levaram-nos a preconizar : o primeiro desbaste aos cinco anos retirando-se as dominadas (que no caso vertente, alcançaram cêrca de um terço da plantação inicial); o segundo, aos sete e meio anos, eliminará as retardatárias. Com isso as árvores que denominamos "médias" tomarão mais vulto equiparando-se às avantajadas. O Corte final (de exploração poderá ser feito no décimo quarto ou décimo quinto ano.

$\mathrm{X}$ ) Todos os que tomam conhecimento da qualidade e quantidade de produtos dizem logo: vamos cultivar cinamo- 
mo; inúmeros fazendeiros já estão estabelecendo seus lotes para os quais as nossas observações foram modestamente contribuindo.

\section{IN MEMORIAM}

Do sr. Francisco Gorga, leal e dedicado auxiliar de nossa Secção Técnica de Horticultura, a cujos cuidados esteve o preparo das mudas em viveiro.

\section{AGRADECIMENTOS}

Ao sr. Frederico Perencin, jardineiro-chefe incumbido dos tratos culturais do bosque experimental.

Aos srs. Clovis Furquim Ferro e Antonio Gorga, pela tomada e registro de medidas diretas nas árvores e pilhas de lenha.

Aọs srs. Meton e Thyrso Cavalcante Maranhão, pelas fotografias. 